VOL. 100 , NO. 418
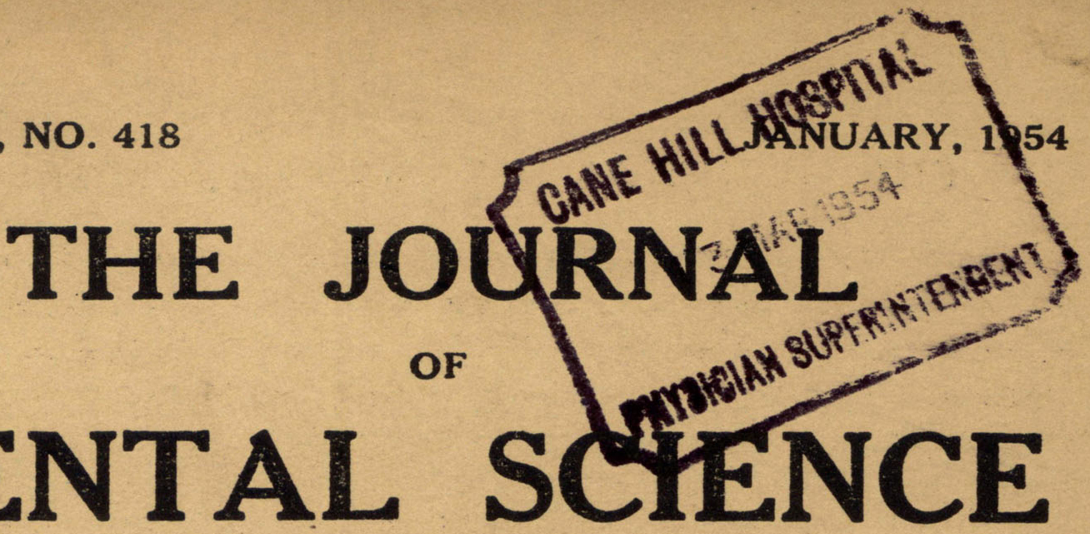

(THE BRITISH JOURNAL OF PSYCHIATRY)

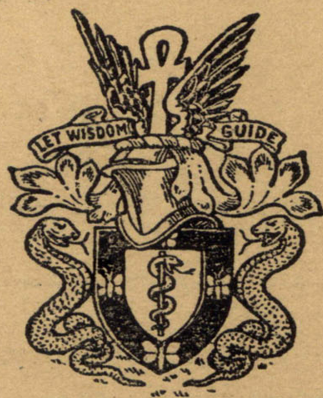

BY AUTHORITY OF

THE ROYAL MEDICO-PSYCHOLOGICAL ASSOCIATION

\author{
EDITOR-IN-CHIEF \\ G. W. T. H. FLEMING \\ WITH THE ASSISTANCE OF \\ Alexancier Walk (Co-editor)
L. C. Cook
P. K. McCowan
F. L. Golla
A. Meyer

R. M. Norman

(The above constitute the Journal Committee)

E. D. Adrian

W. Ross Ashby

Sir F. C. Bartlet

W. E. le Gros Clark

S. M. Coleman

C. J. C. Earl
AND

Sir A. Fleming Lionel S. Penrose A. A. W. Petrie Derek Richter E. T. O. Slater J. N. P. Moore

\title{
LONDON
}

J. \& A. CHURCHILL, LTD

Published Four times Yearly Twelve Shillings and Sixpence net 


\section{THE JOURNAL OF MENTAL SCIENCE}

Communications on general editorial matters, including MSS. for publication, books for review and other printed matter, and communications regarding the Epitome section, including journals to be abstracted, should be sent to the Editor-in-Chief, Barnwood House, Gloucester.

Communications and inquiries regarding sales should be addressed to the Publishers, Messrs. J. \& A. CHURCHILL, Ltd., 104, Gloucester Place, Portman Square, London, W.1; and those regarding Advertisements to the Editor-in-Ghief, Barnwood House, Gloucester. Phone: Gloucester 66292.

Details of membership of the Royal Medico-Psychological Association are obtainable from the Secretary, R.M.P.A., 11 Ghandos Street, Gavendish Square, London, W. 1.

\section{THE ROYAL MEDICO-PSYGHOLOGIGAL ASSOCIATION. PUBLICATIONS.}

From Messrs. Adlard \& Son, Ltd., Bartholomew Press, Dorking, Surrey.

Enquiry (History) Form, for use in Mental Hospitals. In three sizes. Prices and specimen forms on application.

From Messrs. J. \& A. Churchill, Ltd., I04 Gloucester Place, W. I

"The Journal of Mental Science." Published four times a year. Price 12/6. Postage extra.

From Messrs. Baillière, Tindall \& Cox, 8 Henrietta Street, W.C. 2

"Handbook for Mental Nurses." 8th edn. In preparation.

"Manual for Mental Deficiency Nurses." 1931. Price 6/6 net.

"Occupational Therapy." Addendum to "Handbook." 1938. Price 6d.

From the Registrar, R.M.P.A., II Chandos Street, W. I.

"6 Nursing Examination Papers, 1928-38." Price 9d. each. Postage $\mathrm{I}$.

"Regulations for the D.P.M. of the R.M.P.A."

From the Secretary, in Chandos Street, W. 1 .

The Charter and By-Laws of the Association. Price 2/- Postage $1 \frac{1}{2} d$. 


\section{THE OLD MANOR, SALISBURY}

A Private Hospital for the Care and Treatment of those

of both sexes suffering from MENTAL DISORDERS

Extensive grounds. Detached Villas. Chapel. Garden produce from own gardens.

Terms very moderate.

CONVALESCENT HOME AT BOURNEMOUTH

standing in 12 acres of ornamental grounds, with separate villas, tennis courts, etc. Patients or boarders may visit the Home by arrangement.

\section{WYKE HOUSE, ISLEWORTH} MIDDLESEX Tel. EALing 7000

A Private Hospital for individual treatment of all forms of Nervous and Mental Illness, including Alcoholism. Uncertified and certified patients are admitted and particular attention is given to the needs of the aged. This well-known Home for Men and Women is surrounded by attractive and secluded grounds, and all well-tried modern treatments are aviilable.

DR. H. PULLAR-STRECKER DR. G. W. SMITH, O.B.E. 
MENTAL HOSPITALS, INSTITUTIONS, HOMES, ETC.

\section{CHEADLE ROYAL CHEADLE, CHESHIRE}

A Registered Hospital for MENTAL DISEASES, and its Seaside Branch, GLAN-Y-DON, Colwyn Bay, N. Wales.

THE object of this Hospital is to provide the most efficient means for 1 the treatment and care of PRIVATE PATIENTS OF BOTH SEXES suffering from MENTAL and NERVOUS DISEASES.

The Hospital is governed by a Committee appointed by Trustees.

VOLUNTARY, TEMPORARY and CERTIFIED PATIENTS RECEIVED.

For Terms and further information apply to the MEDICAL SUPERINTENDENT. Telephone: GATLEY 2231.

\section{CHISWICK HOUSE \\ A Private Nursing Home for the Treatment and Care of Mental and Nervous Illnesses in both sexes. \\ Telephone : PINNER 234 \\ PINNER, MIDDLESEX}

A modern house, 12 miles from Marble Arch, in attractive, secluded grounds. Fees from 12 guineas per week. inclusive. Patients treated under certificate. Temporary or Voluntary status. Modern forms of treatment, including psychotherapy, narco-analysis, modified insulin, occupational therapy, E.C.T., etc. DOUGLAS MACAULAY. M.D., D.P.M.

\section{HITCHAM PLACE, BURNHAM, BUCKS.}

(late Fenstanton, Christchurch Road, S.W.2)

A Private Home for the Care and Treatment of a limited number of Ladies with Mental and Nervous Disorders. Temporary and Voluntary Patients received. Large Country

Mansion with twenty acres of grounds in Green Belt. Home-like surroundings.

Apply : Dr. Madeline R. Lockwood, Resident Physician. Telephone : Burnham 624.

\section{HAYDOCK LODGE NEWTON-LE-WILLOWS, LANCASHIRE}

For the reception and treatment of PRIVATE PATIENTS of both sexes of the UPPER AND MIDDLE CLASSES suffering from Mental and Nervous Disorders, Alcoholism and Drug Addiction, either voluntary, temporary or under certificate. Patients are classified in separate buildings according to their mental condition.

Situated in park and grounds of 400 acres. Self-supported by its own farm and gardens in which patients are encouraged to occupy themselves. Every facility for indoor and outdoor recreation. For terms, prospectus, etc.. apply MEDICAL SUPERINTENDENT.

Telegraphic Address: "Street." Ashton-in-Makerfield.

'Phone: 7311 Ashton-in-Makerfield.

\section{HEIGHAM HALL, NORWICH}

PRIVATE MENTAL HOME for Nervous and Mental illness. All types of treatment carried out. Accommodation for Alcoholics and Addicts available. Special Geriatric Unit now open.

Fees from 6 gns. per week upwards according to requirements.

Apply to Dr. J. A. SMALL. Telephone: Norwich 20080. 


\section{ADLARD \& SON}

LIMITED

\section{BARTHOLOMEW PRESS} DORKING - SURREY

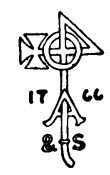

PRINTERS OF THIS :: :: JOURNAL

\section{ESTIMATES SUBMITTED PROMPTLY}

FOUNDED IN 1766, the Firm has continued uninterruptedly, and is able to undertake ALL CLASSES OF PRINTING.

The Staff is Specially Trained in the production of all printed matter connected with Private Hospitals and Homes, Medical, Scientific and other Institutions.

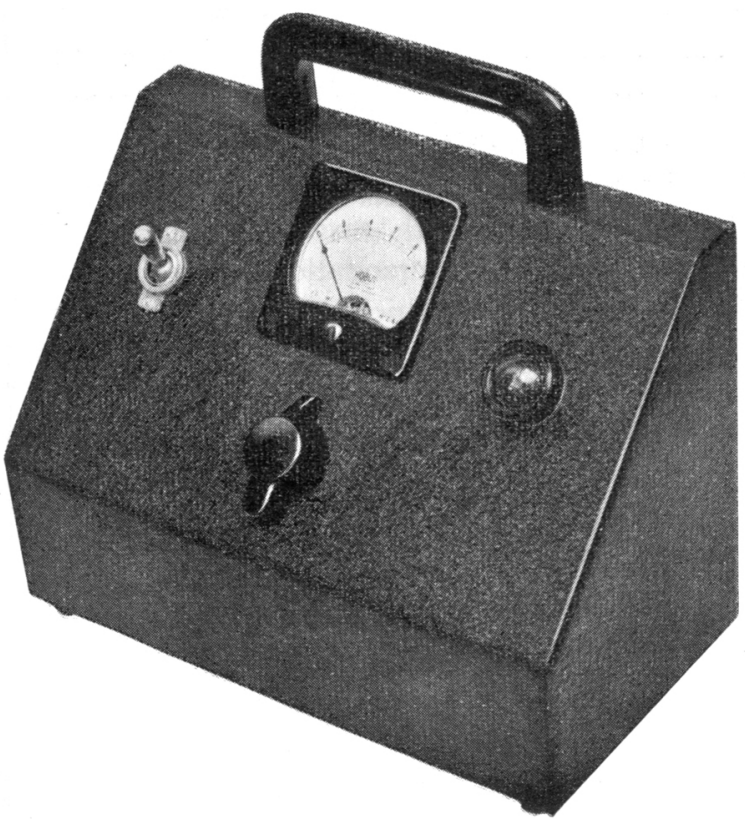

(For A.C. or D.C. Mains
or 12 volt Battery )

Reduces post-ECT confusion and amnesia.

Relieves 'tension' in Ch. Neuroses. Cardiac and respiratory stimulation in Narcotic poisoning and irreversible coma. also:

\section{'ECTRON'}

\section{ELECTRO-CONVULSANT} APPARATUS

'ECTRON' Moulded Rubber Mouth Gag

Write for full details to:

\section{ECTRON LTD.}

REELEK WORKS, BALDOCK, HERTS ENGLAND 


\section{BARNWOOD HOUSE}

GLOUCESTER

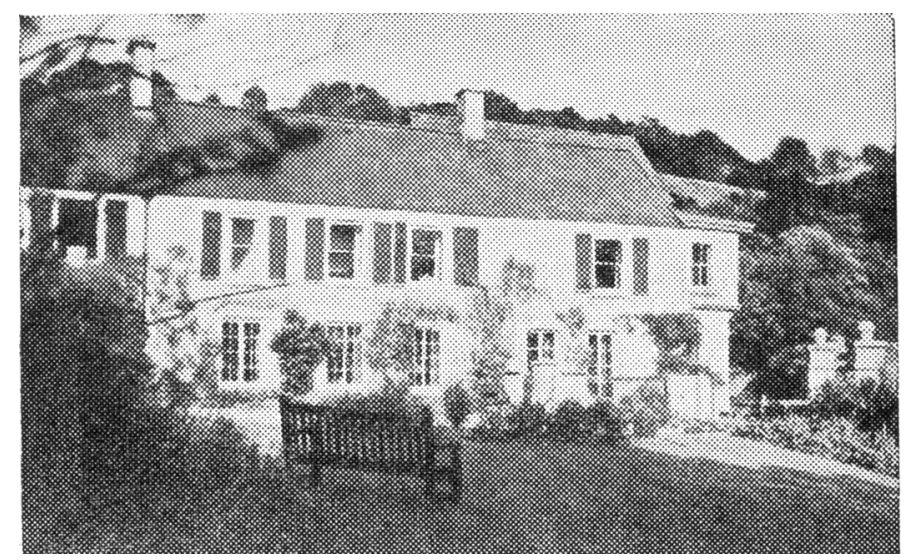

CRICKLEY COURT-ONE OF THE SEPARATE VILLAS

A REGisterED HOSPITAL, (outside the National Health Service) for the GARE and TREATMENT of LADIES and GENTLEMEN suffering from NERVOUS and MENTAL DISORDERS. Within two miles of the Western and London Midland Regional Railway Stations at Gloucester, the Hospital is easily accessible by rail from London and all parts of the United Kingdom. It is beautifully situated at the foot of the Gotswold Hills, and stands in its own grounds of over 300 acres. Voluntary Patients of both sexes are also received for treatment. Special accommodation is also provided at thrce villa residences, all of which stand in their own grounds and are entirely separate from the main Hospital. All the most modern methods of treatment including electric shock and prefrontal leucotomy are used.

For Terms, etc., apply to

G. W. T. H. FLEMING, M.R.G.S., L.R.G.P., D.P.M., Physician Superintendent, who may be seen in London by appointment

Telephone: No. 66207 Glougester 


\section{ELECTRO- \\ ENCEPHALOGRAPH}

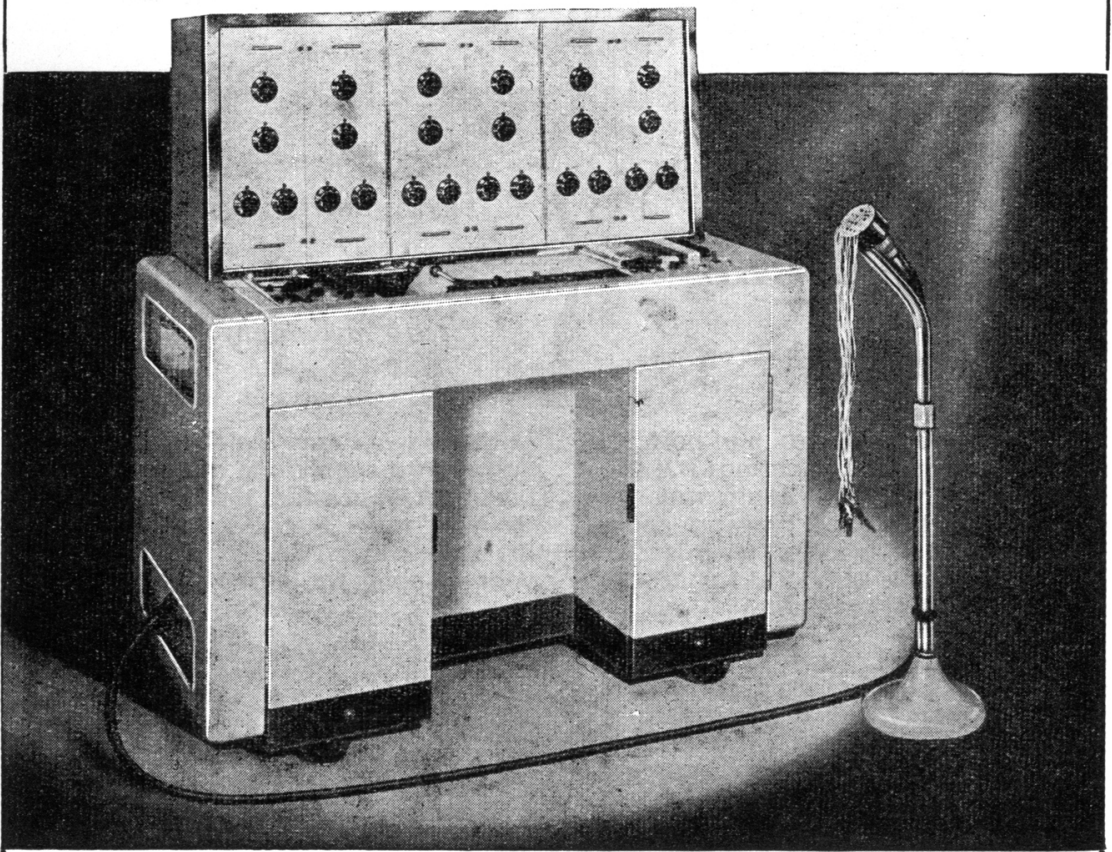

The Marconi 6-channel E.E.G. is the product of unremitting electrical development and exhaustive pre-production trials. In many parts of the world it has gained the confidence of operator and neurologist, many distinctive features contributing to an exemplary performance.

- Adjustable floor-stand with fourteen non-polarisable silver/silver chloride headelectrodes - Balanced high-gain amplifiers - Frequency response extending from a fraction of a cycle up to 75 cycles for direct recording Six-channel 3-speed recorder with marker and timing pens "Universal" amplification up to $5000 \mathrm{c} / \mathrm{s}$ for use with external apparatus.

\section{MARCONI INSTRUMENTS} DIATHERMY · AUDIOMETRY ESECTRO-ENCEPHALOGRAPHY * ELECTRO-CARDIOGRAPHY

MARCONI INSTRUMENTS LTD . ST. ALBANS, HERTS . Phone: St. Albans $6161 / 7$ 30 Albion Street, Kingston-upon-Hull. Phone: Hull Central 16144. 19 The Parade,

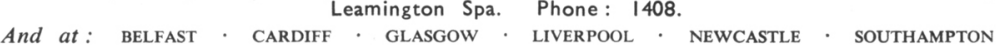
Managing Agents in Export:

MARCONI"S WIRELESS TELEGRAPH CO. LTD., MARCONI HOUSE, STRAND, LONDON, W.C.2. 


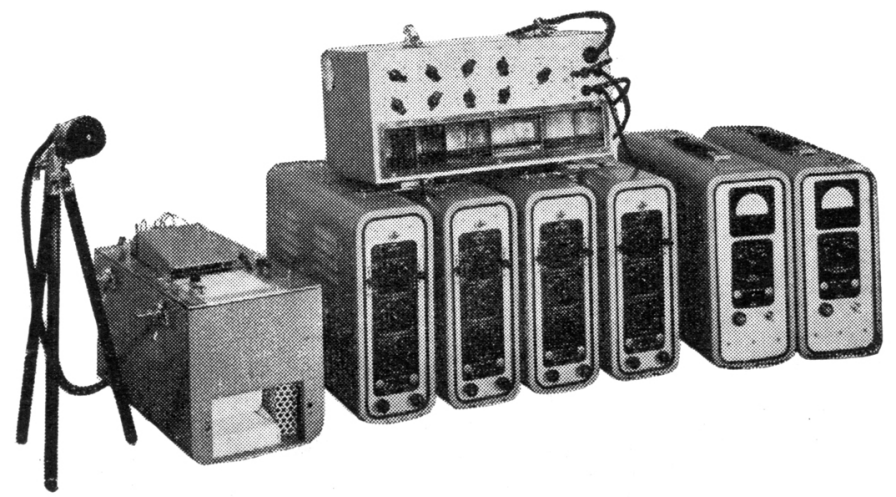

NEW portable

\section{direct-recording}

\section{equipment}

This new, and versatile, group of portable units can be combined in various ways to provide direct-recording equipment for many physiological and physical applications where permanent records are required of variable activity at frequencies below 100 cycles per second.

Using conventional paper, this form of ink recording has a marked economical advantage over continuous film recording of intermittent phenomena, either D.C. or A.C. up to 90 c.p.s. The low recording cost is very important in the case of long recordings, often of one hour duration, when the cost of all other methods is quite prohibitive. The recordings are permanent and visible from the instant of occurrence.

\section{The equipment consists of four units.}

(1) Recorder Unit EPR. (1-4 pen) direct ink-writing pen oscillograph. This unit can be supplied with up to four pen motors as required. The equipment includes ink supply, three-speed paper device, internal load resistances for C.R.O. use and appropriate controls. A seconds time marker is also provided. The unit requires suitable amplifiers for operation as a critically damped high speed oscillograph recorder.

(2) Amplifiar Unit EPA.-High gain-low noise A.C. coupled amplifier push-pull throughout, 5 stages specifically designed for operating the pen recorders as used in the Recorder Unit - EPR. Frequency response $0.35-500$ c.p.s. $-1 \frac{1}{2} \mathrm{db}$. Voltage gain $3 \times 10^{6}$ which corresponds to 10 millimetres for 10 microvolts peak to peak on the Pen Oscillograph.

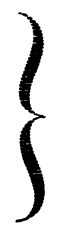

\section{Electro Encephalography \\ Electro Cardiography}

Electro Myography

(3) Stabilised Power Supply Unit-EPP.designed to supply one or two amplifiers type EPA. It provides the H.T. supply for the later stages, the A.C. heater power for the latter valves, and a highly stabilised voltage supply for the early stage heaters.

(4) Input Switch Unit-EPI.- designed to work with the other units in this group. It consists of a Master-Switch for the selection of pre-wired master electrode patterns and also allows individual selection of any electrode to either side of any amplifier input. A Master Calibrator and Balance Switch is also incorporated. A small camera-tripod-type input stand, the head of which accepts up to eleven electrode leads and provides an earth connection, stows away inside the EPI. unit for carriage.

All the units are fully portable, fitted with carrying handles and quickly detachable covers for transport. Finish is grey Moroccoid which is durable and relatively dust free.

FURTHER DETAILS \& PRICES AVAILABLE ON REQUEST

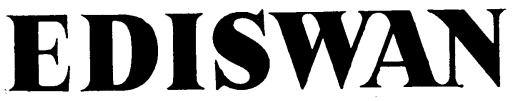

THE EDISON SWAN ELECTRIC CO. LTD I 55 CHARING CROSS RD., LONDON W.C.2 \& BR.ANCHES Tel: GER. 8660 Grams: Ediswan, Westcent, London Member of the A.E.I. Group of Companies 


\section{INSTRUCTIONS TO AUTHORS}

Strict observation of the following requirements will save intending authors considerable time and worry, and will facilitate the publication of papers submitted.

(I) Authors should consult a current issue to see how a paper should be presented. They should consult General Notes on the Preparation of Scientific Papers, published for the Royal Society by the Cambridge University Press, 200, Euston Road, London, N.W.I (price 2s. $9 d$. post free).

(2) The title should be brief and contain no sub-heading. This should be followed by the author's name, his qualifications and his present appointment.

(3) Omit a summary of the literature when this has been adequately summarized elsewhere.

(4) For reasons of economy, case-histories of patients can be published only when they are of exceptional scientific interest.

(5) Diagrams and graphs must be drawn in black ink with properly printed lettering. If they have to be redrawn by the printer, the cost, which may amount to several pounds, will be charged to the author.

(6) Tables and graphs should be kept as few as possible. If they number more than a few, the author must be prepared to pay part of their cost.

(7) Any deviation or difference that might be due to random sampling must, if it is to be discussed in its general, scientific significance, be first shown, by calculation of the appropriate probability, to be significant statistically.

(8) All references should be given at the end of the paper, in alphabetical order, and in the following form :

Sмiтн, A. B., J. Ment. Sci., 1950, 95, 493.

In the body of the paper they should appear as : Smith (I950).

(9) When the proof arrives from the printer it is for the correction of printer's mistakes only. Larger alterations can be made only with the Editor's permission and if the author is willing to defray the cost.

(ro) The author will receive 6 reprints of his paper free of charge. If further reprints are required the order should be sent direct to Messrs. Adlard \& Son, Ltd., Bartholomew Press, Dorking, Surrey.

(II) A paper sent to the Editor-in-Chief is, as a rule, sent to one of the panel of Referees set out on the cover of the Journal for his opinion. Papers are as a rule not rejected until a second or further opinion have been received.

[Facing Ist matter 